\title{
Development and validation of colorimetric method for the quantitative analysis of kanamycin in bulk and pharmaceutical formulation
}

\author{
Malik A. Hussien, Mohamed E. Adam, Shaza W. Shantier*, Elrasheid A.E. Garalnabi and Elrasheed A. Gadkariem
}

Department of Pharmaceutical Chemistry, Faculty of Pharmacy, University of Khartoum, P.O. Box 1996, Khartoum, Sudan .

\begin{tabular}{|c|c|}
\hline ARTICLE INFO & ABSTRACT \\
\hline Article history: & \multirow{8}{*}{$\begin{array}{l}\text { The aim of this study was to develop a simple spectrophotometric method for the determination of Kanamycin } \\
(\mathrm{KM}) \text { in pure bulk form and in its pharmaceutical formulations. Being an amino group containing molecule, KM } \\
\text { reacted with ascorbic acid to form a water soluble, purple-pink, } 1: 1 \text { complex that showed two wavelength } \\
\text { maxima }\left(\lambda_{\max }\right) \text { at } 390 \mathrm{~nm} \text { and } 530 \mathrm{~nm} \text {. The color was developed after heating for } 40 \text { minutes at } 100^{\circ} \mathrm{C} \text { and } \\
\text { remained stable for at least } 48 \text { hours. The validity of developed method was tested by analyzing } \mathrm{KM} \text { under the } \\
\text { optimum experimental conditions. Beer s law was found valid over the concentration range }(40-200 \mu \mathrm{g} / \mathrm{ml}) \text { with } \\
\text { an excellent correlation coefficient (less than } 0.999) \text {. The repeatability and reproducibility results showed a low } \\
\text { relative standard deviation values (RSD } \%<2) \text {, which reflected the precision of the developed method. The } \\
\text { good percentages added recovery ( } 100.09 \pm 0.28 \% \text { and } 99.98 \pm 0.88 \%, \mathrm{n}=3 \text { ) at } 390 \mathrm{~nm} \text { and } 530 \mathrm{~nm} \text {, } \\
\text { respectively, reflected the method freedom from interferences. }\end{array}$} \\
\hline Received on: 05/02/2017 & \\
\hline Accepted on: 19/03/2017 & \\
\hline Available online: $30 / 04 / 2017$ & \\
\hline Key words: & \\
\hline Kanamycin, & \\
\hline Spectrophotometric, & \\
\hline $\begin{array}{l}\text { Determination, Ascorbic } \\
\text { acid, Validation. }\end{array}$ & \\
\hline
\end{tabular}

\section{INTRODUCTION}

Kanamycin (Fig.1) is an aminoglycoside antibiotic obtained from the soil bacterium Streptomyces kanamyceticus, used parenterally in the treatment of various infections, especially those caused by gram-negative bacteria (Pestka, 1975). The coupling reagent (ascorbic acid) was reported to be used for determination of many primary amines containing drugs (Krishna and Sanker, 2007; Adam et al., 2015), penicillins and cephalosporins having $\alpha$-aminoacyl functionality (Gadkariem et al., 2009; EL-Obeid et al., 1999). Although several methods were reported for the analysis of $\mathrm{KM}$ in bulk form, pharmaceutical dosage form, and also in biological fluids (Mahmoud et al., 2013; Mirela et al., 2007, Ahmed et al., 2007; Sekkat et al., 1989; Kim et al., 2001), these methods are either expensive, require many chemical reagents or sophisticated instruments.

\footnotetext{
* Corresponding Author

Email: sshantier@yahoo.com
}

Therefore, the aim of the present work was to develop simple and accurate colorimetric method for the determination of $\mathrm{KM}$ in bulk and pharmaceutical forms using ascorbic acid.

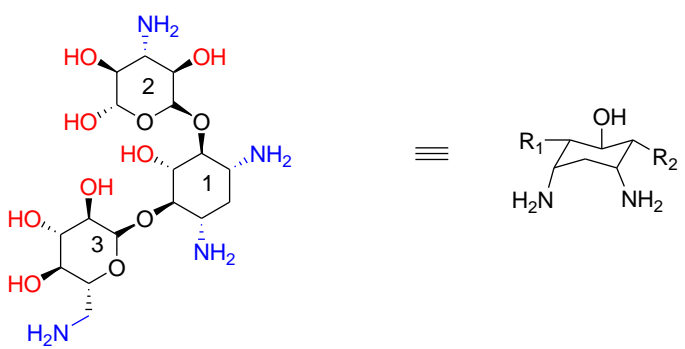

Fig 1: Chemical structure of KM.

\section{MATERIALS AND METHODS}

Reference and sample

KM sulphate RS was obtained from Aladdin Industrial Corporation, Shanghai, China. Kanamycin injection contains kanamycin acid sulphate B.P. equivalent to $1 \mathrm{~g}$ kanamycin base, Shanghai Medicines \& Healthproducts, China. 


\section{Chemicals}

L-ascorbic acid, Labtech chemicals, India. Dimethyl sulphoxide (DMSO; 99.5\%), Fine-chem limited, India. Dimethylformamide (DMF), S.d. Fine-Chem limited, India. Potassium dihydrogen orthophosphate, $\mathrm{CDH}$ (Central Drug House Ltd), Newdelhi, India. Potassium hydroxide, CDH (Central Drug House Ltd), Newdelhi, India. Methanol HPLC grade, CHEMLAB, Belgium.

\section{Instruments}

The spectrophotometric studies were carried on UV Spectrophotometer-1800, Eng240v, Shimadzu, Japan.

\section{METHODOLOGY}

\section{Preparation of Stock Solutions \\ KM standard stock solution}

$0.04 \mathrm{~g}$ of $\mathrm{KM}$ standard was accurately weighed and transferred into $10 \mathrm{ml}$ volumetric flask. The volume was then completed to mark with distilled water (solution A; $4000 \mu \mathrm{g} / \mathrm{ml}$ or $0.4 \% \mathrm{w} / \mathrm{v})$.

\section{KM sample stock solution}

A quantity of $\mathrm{KM}$ powder for injection equivalent to $0.04 \mathrm{~g}$ of $\mathrm{KM}$ was accurately weighed and transferred into $10 \mathrm{ml}$ volumetric flask. The volume was then completed to mark with distilled water (solution B; $4000 \mu \mathrm{g} / \mathrm{ml}$ or $0.4 \% \mathrm{w} / \mathrm{v}$ ).

\section{Coupling reagent solutions (Ascorbic acid)}

Ascorbic acid solution $(0.2 \% \mathrm{w} / \mathrm{v})$ was prepared using different solvents (DMSO and DMF; solution $\mathrm{C}$ and $\mathrm{D}$, respectively).

\section{Blank reagent}

$2 \mathrm{ml}$ of freshly prepared solution $\mathrm{C}$ was added to $0.5 \mathrm{ml}$ distilled water in stoppered glass tube. The volume was then completed to $10 \mathrm{ml}$ with DMSO.

\section{Reaction Conditions Optimization}

\section{Effect of heating time}

Serial volumes from solution A $(0.1-0.5 \mathrm{ml})$ were transferred into five stoppered glass tubes. The volumes were completed to $0.5 \mathrm{ml}$ with distilled water. $2 \mathrm{ml}$ of freshly prepared solution $\mathrm{C}$ and $7.5 \mathrm{ml}$ of DMSO were added to each tube. The above dilutions were repeated four times and heated in a boiling water bath for a time ranged between 20-50 minutes. After cooling to room temperature the absorbance values were measured against the blank reagent.

\section{Effect of different solvents}

Serial dilutions were made from solution A by transferring $0.1 \mathrm{ml}, 0.3 \mathrm{ml}$ and $0.5 \mathrm{ml}$ into three stoppered glass tubes. The volume was then completed to $0.5 \mathrm{ml}$ with distilled water. $2 \mathrm{ml}$ of freshly prepared solution $\mathrm{C}$ and $7.5 \mathrm{ml}$ of DMSO were added to each tube. The solutions were heated for 40 minutes in a boiling water bath. After cooling, the absorbance values were measured against blank at 390 and 530 nm. The above procedure was repeated using solution $\mathrm{D}$ instead of solution $\mathrm{C}$ and the volumes were completed to $10 \mathrm{ml}$ using DMF.

\section{Effect of ascorbic acid concentration}

Two $\mathrm{ml}$ of $0.1 \%, 0.2 \%$ or $0.3 \% \mathrm{w} / \mathrm{v}$ ascorbic acid solution in DMSO were added separately to three stoppered glass tubes containing $0.5 \mathrm{ml}$ of solution A. $7.5 \mathrm{ml}$ of DMSO was added to each tube and the solutions were heated in a boiling water bath for 40 minutes. After cooling at room temperature, the absorbance values were measured against the blank reagent.

\section{Construction of Calibration Curve:}

Serial aliquots of solution A $(0.1-0.5 \mathrm{ml})$ were transferred into five stoperred glass tubes. The volumes were completed to $0.5 \mathrm{ml}$ with distilled water. $2 \mathrm{ml}$ of freshly prepared solution $\mathrm{C}$ were added to each flask. The volumes were then completed to 10 $\mathrm{ml}$ with DMSO. The mixture solutions were heated for 40 minutes in a boiling water bath. After cooling, the solutions were scanned at $350-600 \mathrm{~nm}$ against the blank. The measured absorbance values at $390 \mathrm{~nm}$ and $530 \mathrm{~nm}$ were plotted against the corresponding concentrations to obtain the calibration curve.

Solution B was also treated as under calibration curve. The injection content was determined by the slope ratio method and direct sample/ standard comparison.

\section{Method precision}

The precision of the developed method was evaluated by the repeatability and reproducibility results. Different concentrations within the linearity range were analysed three times in the same day and between-days. The relative standard deviation (RSD) was then calculated.

\section{Percentage Added recovery}

$0.2 \mathrm{ml}$ of each solution $\mathrm{A}$ and $\mathrm{B}$ was transferred into separate stoppered glass tubes. $0.2 \mathrm{ml}$ of solution A was mixed with $0.2 \mathrm{ml}$ of solution $\mathrm{B}$ in a third tube. These solutions were treated as under calibration curve and the percentage recovery was calculated (Adam et al., 2016).

\section{Molar ratio method for determination of the stoichiometry}

In a volumetric flask $(10 \mathrm{ml}), 0.034 \mathrm{~g}$ of $\mathrm{KM}$ standard was dissolved in distilled water (concentration $5.0 \times 10^{-3} \mathrm{M}$ ). Then $0.1 \mathrm{ml}, 0.2 \mathrm{ml}, 0.3 \mathrm{ml}, 0.4 \mathrm{ml}, 0.5 \mathrm{ml}, 0.6 \mathrm{ml}, 0.7 \mathrm{ml}, 0.8 \mathrm{ml} \& 1 \mathrm{ml}$ of this solution were transferred into nine stoppered glass tubes. Distilled water was added to adjust the volumes to $1.0 \mathrm{ml} .0 .4 \mathrm{ml}$ of freshly prepared ascorbic acid solution $\left(5.0 \times 10^{-3} \mathrm{M}\right)$ was added to each tube and the volumes were then completed to $10 \mathrm{ml}$ with DMSO. The above solutions were heated for 40 minutes in a boiling water bath at $100{ }^{\circ} \mathrm{C}$. After cooling, the absorbance values were measured at $530 \mathrm{~nm}$ and $390 \mathrm{~nm}$ against the blank. 


\section{RESULTS AND DISCUSSION}

$\mathrm{KM}$ is composed of 2-deoxystreptamine (aminocyclitol moiety) glycosidically linked to amino sugars. It exhibits weak UV- absorption, thus a suitable chromogen is needed to obtain a more UV/VIS light absorbing chromophore that can be useful as a sensitive spectrophotometric method for its determination in bulk and dosage forms.

Ascorbic acid, naturally occurring cheap organic compound (sugar acid), was found to react with KM in presence of DMSO to produce pink -purple colored complex absorbing at $390 \mathrm{~nm}$ and 530nm. The different experimental factors affecting the color development, intensity and stability were studied.

These factors include the solvent, the reagent concentration, the reaction time and temperature. During the study of the effect of different solvents on the color formation and stability, solutions of variable color intensities were obtained. In an attempt to reach an explanation for this observation on the reaction process, the effect of two solvents of different dielectric constants (D.E.) were studied (Table 1). The results obtained reflected that a hyperchromic effect was observed with the solvent with higher D.E. (DMSO). An assumption was drawn that DMSO with its medium polarity (DE 47) possibly enhances the reactivity of the ascorbic acid and stabilizes the formed $\pi$ to $\pi^{*}$ and $n$ to $\pi^{*}$ transitions.

The optimal volume and concentration for ascorbic acid to give satisfactory results were found to be $1.0 \mathrm{ml}$ of $0.2 \% \mathrm{w} / \mathrm{v}$ in DMSO. The results obtained for heating effect are shown in figure 2. A fixed time of 40 minutes was established as the most suitable time (best r-value and color intensity) to give reproducible absorbance values with low standard deviations.

Table 1: Effect of different solvents on the formation of kanamycin-ascorbic acid complex.

\begin{tabular}{cccc}
\hline KM conc. $(\boldsymbol{\mu} \mathbf{g} / \mathbf{m l})$ & $\lambda_{\max }(\mathbf{n m})$ & Absorbance in DMF & Absorbance in DMSO \\
\hline 40 & 390 & 0.125 & 0.226 \\
& 530 & 0.043 & 0.076 \\
\hline 120 & 390 & 0.420 & 0.714 \\
& 530 & 0.142 & 0.238 \\
\hline 200 & 390 & 0.652 & 0.851 \\
& 530 & 0.219 & 0.382 \\
\hline
\end{tabular}
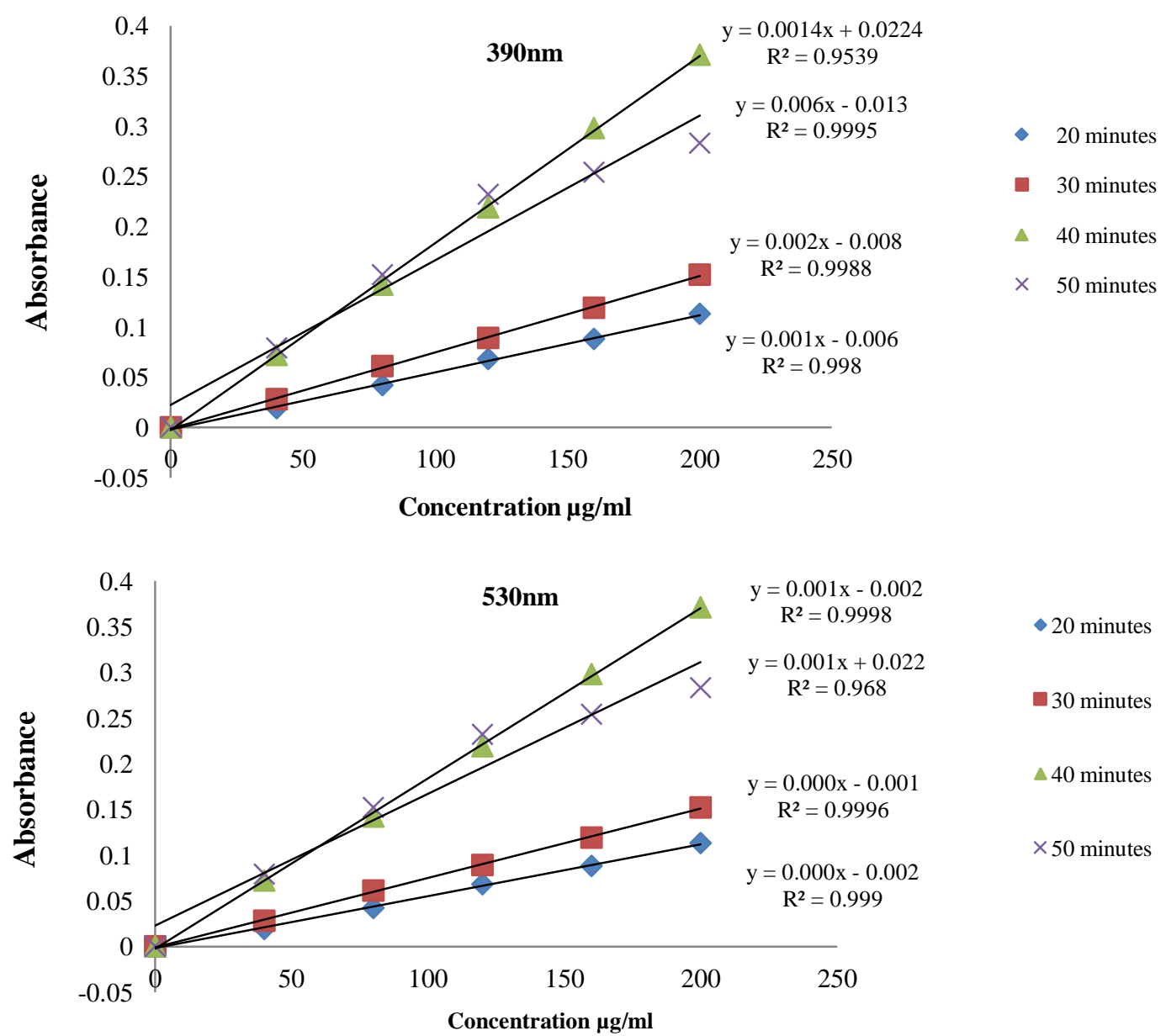

Fig. 2: Effect of heating time on colored product formation. 

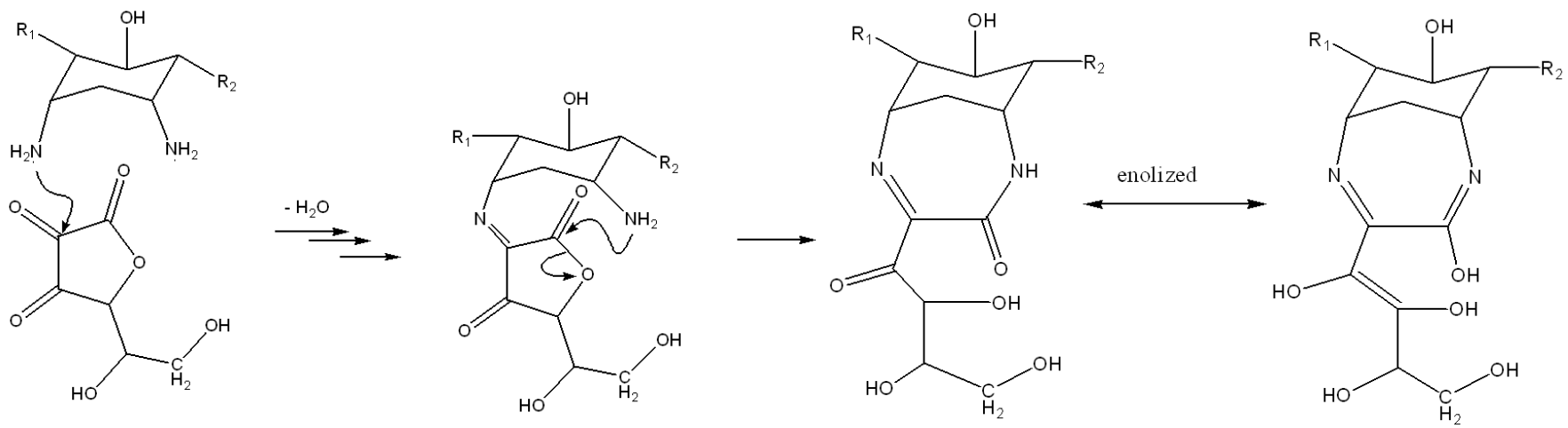

Scheme 1: Proposed pathway for KM-ascorbic acid complex formation.

\section{Method validation Linearity}

Under the optimum experimental conditions, Beer's law was valid over the concentration range $(40-200 \mu \mathrm{g} / \mathrm{ml})$ of $\mathrm{KM}$. The corresponding regression equations at $390 \mathrm{~nm}$ and $530 \mathrm{~nm}$ were $\mathrm{A}=$ $0.007+0.0058 \mathrm{C}(\mathrm{r}=0.9992)$ and $\mathrm{A}=0.002+0.0019 \mathrm{C}(\mathrm{r}=$ 0.999), respectively, which indicate an excellent linearity. The detection limits were $8.58 \mu \mathrm{g} / \mathrm{ml}$ and $9.6 \mu \mathrm{g} / \mathrm{ml}$ at $390 \mathrm{~nm}$ and $530 \mathrm{~nm}$, respectively which represent the minimum absorbance value that can be measured for the color produced by complex. The limits of quantification were $32.15 \mu \mathrm{g} / \mathrm{ml}$ and $28.6 \mu \mathrm{g} / \mathrm{ml}$ at $390 \mathrm{~nm}$ and $530 \mathrm{~nm}$, respectively.

\section{Accuracy and precision}

The accuracy of the developed method and freedom from interference by the injection excipients was confirmed by the obtained results for recovery testing of added amount of authentic $\mathrm{KM}$ to the injection solution in ratio of $1: 1$. The results showed good recovery for the injection $(100.76 \pm 1.2 \%$ and $100.6 \pm 1.96 \%$, $\mathrm{n}=3$ at $390 \mathrm{~nm}$ and 530 $\mathrm{nm}$, respectively).

The precision of the developed method was determined on three different concentrations of KM. The results obtained showed a low relative standard deviation values (RSD) varying from 2.30 to $0.38 \%$; $n=3$, which reflect that the developed method is satisfactory repeatable and reproducible.

\section{Application of the developed method}

The developed method was applied for drug content testing in $\mathrm{KM}$ injection. The results were found to be $100.09 \pm$ $0.28 \%$ and $99.98 \pm 0.88 \%, \mathrm{n}=3$ at $390 \mathrm{~nm}$ and $530 \mathrm{~nm}$, respectively.

The accuracy of the proposed method was tested against the official biological assay method for KM (Eu.P., 2012). The biological assay method results gave a100\% potency; this result was taken as the true mean $(\mu)$. The formula for t-value calculation when true mean is known was used (Shantier et al., 2011).

The calculated t-value $(0.29$ and 0.037 at $390 \mathrm{~nm}$ and $530 \mathrm{~nm}$, respectively for 2 degrees of freedom) was less than the tabulated $t$-value, which indicates no significant difference between the chemical and biological methods.

\section{Reaction stoichiometry}

The reaction stoichiometry was found to be a 1:1 ratio reaction using the molar ration method. Accordingly, the proposed reaction pathway between the drug and the reagent is expected to proceed through a nucleophilic addition and acyl substitution between the two cis and equatorial amino group of the drug and the carbonyl group and lactone functionality of the reagent as illustrated in Scheme 1.

\section{CONCLUSION}

Ascorbic acid was found to be a suitable reagent for the determination of KMin pure form and in its dosage forms without interference from the excipients. Thus, the developed method is simple, accurate and precise method and can be used for the routine quality control analysis of KM.

\section{Financial support and sponsorship: NIL.}

Conflict of Interests: There are no conflicts of interest.

\section{REFERENCES}

Adam ME, Shantier SW, Reem S, Mohamed MA and Gadkariem EA. Development of colorimetric method for determination of gabapentin using ascorbic acid as chromogen. J. Chem. Pharm. Res., 2016, 8 (12): 131-135.

Adam ME, Shantier SW, Alfangari SA and Gadkariem EA. Development of Spectrophotometric Method for the Assay of Aminocaproic Acid in Dosage Forms Using Ascorbic Acid. Chem. Sci. Trans., 2015, 4(2): 580-586.

Ahmed AS, Ahmed HM. Islam AF, Qureshi SZ. A simple and selective kinetic spectrophotometric method for the determination of kanamycin using acetylacetone-formaldehydereagent in N,N- dimethyl formamide medium. J. Anal. Chem. 2006; 61(9): 870874.

EL-Obeid HA, Gadkariem EA, AL-Rashood KA, AL-Khamees HA, EL-Shafie FS, Bawazeer GAM. A selective colorimetric method for the determination of penicillin and cephalosporin with $\alpha$-amino acyl functions. Anal. Lett. ,1999, 32(14): 2809-2823.

European Pharmacopiea, EDQM, $5^{\text {th }}$ edition, 2012, p.1867.

Gadkariem E A, Mutasim M M, Ibrahim K E and El-Obeid H A. Spectrophotometric methods for determination of cefprozil in bulk and dosage forms. J Biomed Sci., 2009, 5: 267-274.

Kim BH, Kim YK, OK JH. Development of liquid chromatographic method for the analysis of kananmycin using 
phenylisocyanate reagent. J Chroma. B Biomed Sci Appl., 2001; 752(1): 173-177.

Krishna MV and Sanker DG. Optimization and validation of quantitative spectrophotometric methods for the determination of alfuzocin in pharmaceutical formulations. E-J. Chem., 2007, 4(3): 397-407

Mahmoud. A, Omer, Nagy DM, Mahmoud A. H. Validated spectrophotometric methods for determination of certain aminoglycosides in pharmaceutical formulations. J. Appl. Pharm. Sci., 2013; 3(3):151-161

Mirela FL, Mladen L and Vladimir VH. Synthesis of 2, 6dimethyl-3,5-dimethoxycarbonyle-1,4-dihydropyridine. J. of Mol., 2007; 12: 2546-2558

Pestka, S. 1975. The use of inhibitors in studies on protein synthesis. Text book of Methods in Enzymology. 30: p. 261-282.

Sekkat M, Fabre H, Buochberg MS, Mandrou B. Determination of aminoglycosides in pharmaceutical formulations-thin layer chromatography. J. Pharm. Biomed. Anal., 1989; 7(12): 88- 92.

Shantier SW, Gadkariem EA, Ibrahim KE. Colorimetric Method for the Determination of Tobramycin Int. J. Dr. Form. Res., 2011; 2 (4): 260-272.

\section{How to cite this article:}

Hussien M, Adam ME, Shantier SW, Garalnabi E, Gadkariem E. Development and validation of colorimetric method for the quantitative analysis of kanamycin in bulk and pharmaceutical formulation. J App Pharm Sci, 2017; 7 (04): 163-167. 